PREPARED FOR THE U.S. DEPARTMENT OF ENERGY, UNDER CONTRACT DE-AC02-76CH03073

PPPL-3586

PPPL-3586

UC-70

NSTX Diagnostics for Fusion Plasma Science Studies

by

R. Kaita, D. Johnson, L. Roquemore, M. Bitter, F. Levinton,

F. Paoletti, D. Stutman, and the NSX Team

July 2001

NM|

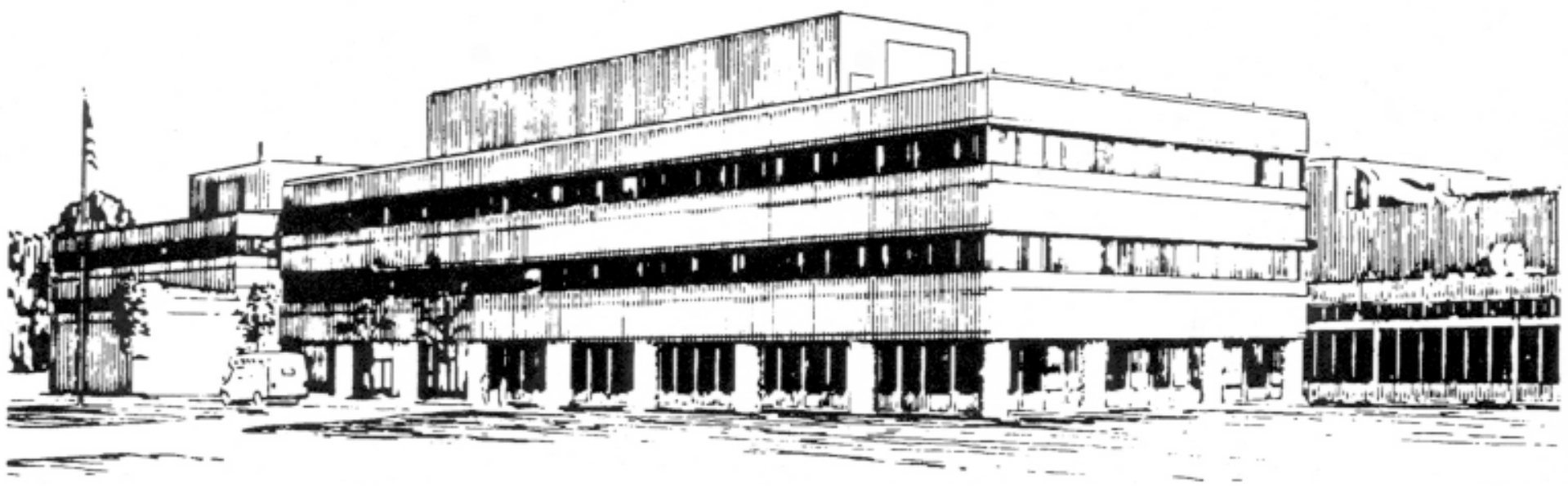

PRINCETON PLASMA PHYSICS LABORATORY PRINCETON UNIVERSITY, PRINCETON, NEW JERSEY 


\section{PPPL Reports Disclaimer}

This report was prepared as an account of work sponsored by an agency of the United States Government. Neither the United States Government nor any agency thereof, nor any of their employees, makes any warranty, express or implied, or assumes any legal liability or responsibility for the accuracy, completeness, or usefulness of any information, apparatus, product, or process disclosed, or represents that its use would not infringe privately owned rights. Reference herein to any specific commercial product, process, or service by trade name, trademark, manufacturer, or otherwise, does not necessarily constitute or imply its endorsement, recommendation, or favoring by the United States Government or any agency thereof. The views and opinions of authors expressed herein do not necessarily state or reflect those of the United States Government or any agency thereof.

\section{Availability}

This report is posted on the U.S. Department of Energy's Princeton Plasma Physics Laboratory Publications and Reports web site in Calendar Year 2001. The home page for PPPL Reports and Publications is: http://www.pppl.gov/pub_report/

DOE and DOE Contractors can obtain copies of this report from:

U.S. Department of Energy

Office of Scientific and Technical Information

DOE Technical Information Services (DTIS)

P.O. Box 62

Oak Ridge, TN 37831

Telephone: (865) 576-8401

Fax: (865) 576-5728

Email: reports@adonis.osti.gov

This report is available to the general public from:

National Technical Information Service

U.S. Department of Commerce

5285 Port Royal Road

Springfield, VA 22161

Telephone: 1-800-553-6847 or

(703) 605-6000

Fax: (703) 321-8547

Internet: http://www.ntis.gov/ordering.htm 


\title{
NSTX DIAGNOSTICS FOR FUSION PLASMA SCIENCE STUDIES*
}

\author{
R. Kaita, D. Johnson, L. Roquemore, M. Bitter, F. Levinton, ${ }^{\#}$ F. Paoletti, ${ }^{@}$ D. Stutman, ${ }^{\S}$ \\ and the NSTX Team \\ Princeton Plasma Physics Laboratory, Princeton University, \\ P. O. Box 451, Princeton NJ 08543 USA
}

\begin{abstract}
This paper will discuss how plasma science issues are addressed by the diagnostics for the National Spherical Torus Experiment (NSTX), the newest large-scale machine in the magnetic confinement fusion (MCF) program. The development of new schemes for plasma confinement involves the interplay of experimental results and theoretical interpretations. A fundamental requirement, for example, is a determination of the equilibria for these configurations. For MCF, this is well established in the solutions of the Grad-Shafranov equation. While it is simple to state its basis in the balance between the kinetic and magnetic pressures, what they are as functions of space and time are often not easy to obtain. Quantities like the plasma pressure and current density are not directly measurable. They are derived from data that are themselves complex products of more basic parameters. The same difficulties apply to the understanding of plasma instabilities. Not only are the needs for spatial and temporal resolution more stringent, but the wave parameters which characterize the instabilities are difficult to resolve. We will show how solutions to the problems of diagnostic design on NSTX, and the physics insight the data analysis provides, benefits both NSTX and the broader scientific community.
\end{abstract}

\section{INTRODUCTION}

The goal of fusion plasma science is to understand the plasma state under thermonuclear conditions. Significant progress has been made in achieving such plasmas in magnetic confinement fusion (MCF) devices. Significant fusion power output has been obtained in the Tokamak Fusion Test Reactor (TFTR)[1] and the Joint European Torus (JET)[2] using deuterium and tritium. These plasmas were characterized by high temperature, low collisionality, and confinement times required for thermonuclear reactors.

TFTR and JET are toroidal MCF devices (tokamaks) with high toroidal fields and aspect ratios, or large torus diameters compared to their plasma cross sections. While they have demonstrated their effectiveness in confining thermonuclear plasmas, these devices have low beta, or ratio of the plasma pressure to the pressure of the magnetic confining field. This does not extrapolate favorably to reactor scale devices.
Recently, a main focus of MCF research has been on a more efficient concept. The spherical torus (ST) is an attempt to confine high pressure plasmas using modest magnetic fields in a compact device. The largest ST in the US fusion program is the National Spherical Torus Experiment (NSTX). The parameters typical of plasmas obtained to date are as follows. The electron density and electron temperature are $\mathrm{n}_{\mathrm{e}} \leq 5 \times 10^{13} \mathrm{~cm}^{-3}$ and $\mathrm{T}_{\mathrm{e}} \leq 1.5$ $\mathrm{keV}$, respectively. The plasma current is $\mathrm{I}_{\mathrm{p}} \leq 1.2 \mathrm{MA}$, and the toroidal magnetic field on axis is $\mathrm{B}_{\mathrm{t}} \leq 0.6$ Tesla. Plasma heating is achieved with inductive Ohmic heating, up to $6 \mathrm{MW}$ of radio frequency power in the ion cyclotron range of frequencies, and neutral beam injection up to 5 MW.

Studies of the magnetohydrodynamic (MHD) stability of toroidal plasmas have shown that the maximum stable beta depends on the aspect ratio.[3] This is an important characteristic of the ST, and the mission of NSTX is to test this prediction. Plasma diagnostics are critical to determining if stable high beta plasmas have been achieved. Thus far, betas on the order of $20 \%$ have been obtained, the goal is to double this to about $40 \%$. This is about an order of magnitude higher than values typical of large aspect ratio devices.

Detailed measurements of NSTX parameters are critical to the reconstruction of plasma equilibria. Identification of MHD modes for comparison with theoretical predictions for the stability of these equilibria is also important for understanding NSTX plasmas.

There are many diagnostics on NSTX, as listed in Table 1 . Most of them were chosen because they provide the first set of data that a new toroidal confinement device requires. Perhaps the most fundamental empirical measure of machine performance is its global energy confinement time. This depends on the plasma density and the electron and ion temperatures.

Energy loss mechanisms include impurities as well electrons and ions, so impurity diagnostics are required. Large scale magntohydrodynamic instabilities and turbulent microinstabilities also affect confinement. Measurements of edge parameters are needed for a complete picture of energy balance.

Our intention is to focus on a few examples of NSTX diagnostics in this paper, and show how they are designed to increase our understanding fusion plasmas. We also discuss the measurement challenges posed by the special characteristics of NSTX.

\footnotetext{
*Work supported by USDOE Contract No. DE-AC02-76-CHO3073.

"Nova Photonics Inc., Princeton NJ 08540 USA

${ }^{\circledR}$ Columbia University, New York NY, 10027 USA

§Johns Hopkins University, Baltimore MD 21218 USA
} 
Table 1. NSTX diagnostics presently operational or nearing completion

\begin{tabular}{|c|c|}
\hline Type & Diagnostic \\
\hline \multirow{7}{*}{ Plasma Confinement } & $2 \mathrm{~mm}$ interferometer \\
\hline & X-ray pulse height analysis \\
\hline & X-ray crystal spectrometer \\
\hline & $\begin{array}{c}\text { Electron Bernstein wave } \\
\text { radiometer }\end{array}$ \\
\hline & Thomson scattering \\
\hline & $\begin{array}{l}\text { Far infrared tangential } \\
\text { interferometer/polarimeter }\end{array}$ \\
\hline & $\begin{array}{l}\text { Charge exchange recombination } \\
\text { spectrometer }\end{array}$ \\
\hline \multirow{2}{*}{ Nonthermal Particles } & Fast ion loss probe \\
\hline & $\begin{array}{l}\text { Scanning neutral particle } \\
\text { analyzer }\end{array}$ \\
\hline \multirow[t]{6}{*}{ Impurities } & Visible spectrometer (VIPS) \\
\hline & $\begin{array}{r}\text { Vacuum ultraviolet survey } \\
\text { spectrometer (SPRED) }\end{array}$ \\
\hline & $\begin{array}{l}\text { Grazing incidence spectrometer } \\
\text { (GRITS) }\end{array}$ \\
\hline & Tangential bolometer array \\
\hline & $\begin{array}{l}\text { Single channel visible } \\
\text { bremsstrahlung detector }\end{array}$ \\
\hline & Filtered fiberscopes \\
\hline \multirow[t]{6}{*}{ MHD Equilibrium } & Flux loops \\
\hline & Rogowski current coils \\
\hline & Magnetic pickup coils \\
\hline & Fast plasma TV \\
\hline & \begin{tabular}{|c|}
$\begin{array}{c}\text { Motional Stark effect } \\
\text { polarimeter }\end{array}$ \\
\end{tabular} \\
\hline & X-ray pinhole camera \\
\hline \multirow[t]{3}{*}{ Plasma Instabilities } & Soft X-ray arrays \\
\hline & Reflectometer array \\
\hline & Locked MHD mode coils \\
\hline \multirow[t]{8}{*}{ Edge Conditions } & Infrared cameras \\
\hline & Fast scanning Langmuir probe \\
\hline & Scrapeoff layer reflectometer \\
\hline & Edge reflectometer \\
\hline & Stationary Langmuir probes \\
\hline & Edge coupons \\
\hline & Fast edge imaging with gas puff \\
\hline & 1- dimensional $\mathrm{H}_{\alpha}$ CCD camera \\
\hline
\end{tabular}

\section{DIAGNOSTICS FOR DETERMINING PLASMA EQUILIBRIA}

The basic equilibrium condition in an MCF device represents a force balance between the plasma and the confining magnetic field.

$$
j x B=\nabla p
$$

Eq. 1

For an axisymmetric toroidal machine like NSTX, it is convenient to use a coordinate system where $\mathrm{R}$ is the distance from the center of the torus to the plasma axis, $\mathrm{Z}$ normal to $\mathrm{R}$, and $\phi$ is the toroidal angle. Equation 1 can then be rewritten as the Grad-Shafranov equation.[4]

$$
\Delta * \psi=-\frac{4 \pi}{c} R J_{\phi}=-\frac{4 \pi}{c} R^{2} \frac{d p}{d \psi}-g(\psi) \frac{d g}{d \psi} . \quad \text { Eq. } 2
$$

Here, $\psi$ is the stream function proportional to the poloidal flux, $\mathrm{J}_{\phi}$ is the current density, and the special operator $\Delta^{*}$ is defined as follows.

$$
\Delta^{*}=R^{2} \nabla \frac{1}{R^{2}} \nabla=R \frac{\partial}{\partial R}\left(\frac{1}{R} \frac{\partial}{\partial R}\right)+\frac{\partial^{2}}{\partial Z^{2}} .
$$

The functions $\mathrm{p}(\psi)$ and $\mathrm{g}(\psi)=\mathrm{RB}_{\phi}$ correspond to the plasma and magnetic field terms respectively. These free functions plus the boundary define the plasma equilibrium.
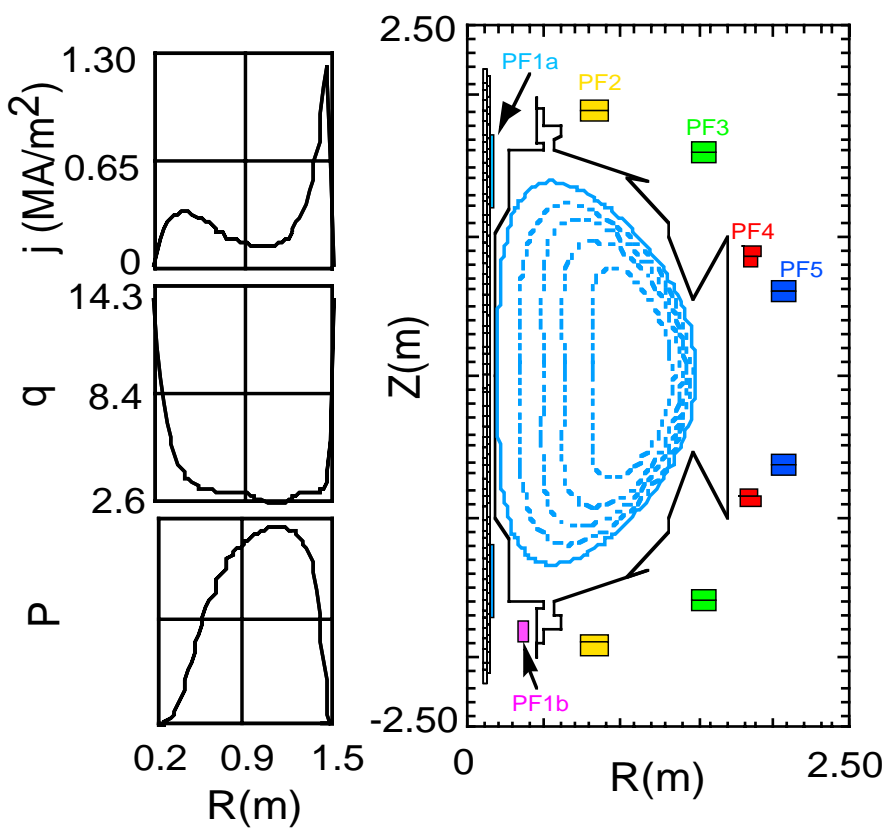

Figure 1. Profiles of current density (j), "safety factor" (q), and pressure (P) (left) and magnetic flux surfaces (right) for high beta NSTX plasma.

A prediction for a high beta (40\%) NSTX equilibrium is shown on the right side of Fig. 1, based on plasma profiles on the left side of the figure. In practice, equilibria are determined by adjusting a trial plasma current profile computationally. This is done in a way that is consistent with global parameters, like the plasma current $\left(\mathrm{I}_{\mathrm{p}}\right)$, and magnetic signals from sensors that are external to the plasma.[5]

The $I_{p}$ is measured with a Rogowski coil, which consists of \#30 gauge magnet wire wound around a thin, flexible Teflon mandrel in the NSTX case.[6] The Rogowski coil follows a poloidal path that encloses the vacuum vessel. The magnetic signals are obtained from flux loops, which are wires mounted in the toroidal 
direction around the vacuum vessel, and discrete magnetic pickup coils. The effects of currents induced in the conducting structures on the magnetic signals are compensated for by measuring the sensor responses as the magnetic field coils are energized in the absence of plasmas.

The sensors on the outer plasma facing components, such as the divertor plates and passive plates indicated in Fig. 2, and the wall of the vacuum vessel behind them, were not difficult to install. The passive plates consist of carbon tiles mounted on large copper plates, and their stabilizing effect is achieved through electromagnetic coupling with the plasma. The divertor plates are similarly designed, and they are the strike points for the open magnetic field lines at the plasma boundary.

The flux loops are mounted in tubes pressed into grooves on the back of the copper plates. A similar array of tubes is located on the inside and outside surfaces of the vacuum vessel. Additional loops are mounted on the poloidal field coils, which are shown as the dark squares marked with an "X" outside the vacuum vessel in Fig. 2. The magnetic pickup coils are made of copper wire wound around a ceramic form. The passive plates have twelve spaces in the toroidal direction, which are bridged by copper jumpers to provide electrical continuity. The pickup coils are placed in these gaps, and also on the vacuum vessel wall between the upper and lower passive plates.

Locating diagnostics in the center stack $(\mathrm{CS})$ region (left side of Fig. 2) is more of a challenge. The CS is an integrated structure containing the buswork that completes the toroidal field coils, and the solenoid for the inductive (Ohmic) plasma heating. This is surrounded by a thermal insulating layer and an inconel shell that forms the inner vacuum vessel wall. The wall is covered with a thin metallic heat shield and carbon tiles, which form the plasma facing surface. The total CS radius is only 18.5 $\mathrm{cm}$.

There is a $3.4 \mathrm{~mm}$ gap between the Ohmic heating solenoid and the thermal insulation covering it. Flux loops encircling the CS and the Rogowski coil segment that follows the CS had to be specially designed to fit in this tight space. The magnetic pickup coils are required to be as close as possible to the plasma for maximum signal and frequency response. They are thus embedded in CS carbon tiles. These tiles are $1.3 \mathrm{~cm}$ thick, however, and the space for the sensors was only half this size. While the coils are not directly exposed to the plasma, they had to be designed for temperatures up to $600^{\circ} \mathrm{C}$ as well as compactness. The latest version consists of bare copper wire on a rectangular MACOR mandrel, coated with a high temperature ceramic adhesive.

Although equilibrium reconstructions are possible without internal magnetic field measurements, there are many cases where global parameters to do not correspond to unique plasma configurations. This is particularly true in discharges with non-monotonic current profiles, which are characteristic of advanced toroidal plasma regimes.[7,8] For this reason, NSTX is implementing a motional Stark effect (MSE) polarimetry diagnostic.[9]

In the MSE technique, the trajectory of neutral deuterium heating beam is viewed by an array of detectors.
They are used to measure the spectral splitting of the Balmer- $\alpha$ line into othogonally polarized components. This Stark splitting is a result of the strong electric field in the rest frame of the injected deuterium atoms, induced by their motion through the confining magnetic field $\left(\mathrm{E}=\mathrm{v}_{\mathrm{B}} \mathrm{xB}\right)$. Detecting the polarization angle of one of these components provides a measure of the magnetic field direction at the region in the plasma where the detector sightline intersects the beam trajectory. The current density at that location can then be deduced. On NSTX, the detector array consists of 20 fiber optic bundles, providing spatial resolution of $2.5 \mathrm{~cm}$ at the edge and 3.0 $\mathrm{cm}$ in the core of the plasma.

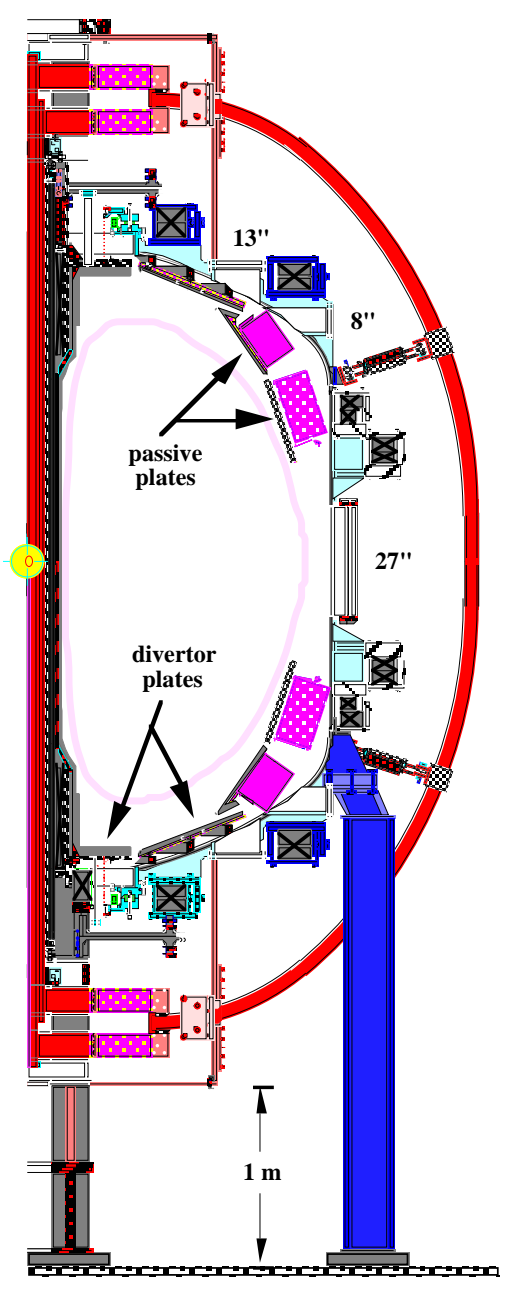

Figure 2. Elevation of NSTX showing passive plates, divertor surfaces, and center stack.

Measurements with the MSE diagnostic have been made only in high aspect ratio MFE devices up to now, where the magnetic fields have been about $0.8 \mathrm{~T}$ or greater. The challenge on NSTX is to externd this technique to lower fields, where spectrally isolating the polarization components is expected to be difficult. The first step is to reduce the Doppler broadening of the individual components by minimizing the spread in angles between the beam and the viewing aperture. The viewing aperture in the horizontal dimension will be 
narrowed. To compensate for the decrease in signal this will cause, the aperture is elongated. In addition, a birefringent filter is being developed, based on a Lyot design currently utilized in solar spectroscopy and dye laser tuning. The goal of this development is an effective passband width of $0.075 \mathrm{~nm}$, or an order of magnitude better than standard interference filters.

The polarization fractions this system is expected to resolve is within a factor of two of present MSE systems, and this will be compensated with higher throughput optics.

A variant of the MSE technique uses lasers for beam excitation instead of collisions with the background plasma, and it avoids the Doppler broadening problem. A laser induced fluorescence (LIF) version of MSE polarimetry is under development, using a tunable laser. A small hydrogen neutral beam will be injected with a coaxial tunable laser resonant with the Doppler shifted $\mathrm{H}_{\alpha}$ transition. With a narrow spectral width, polarization fractions near unity are predicted even at the low fields of NSTX. LIF in laboratory plasmas have demonstrated good signal to noise, and tests are in progress with a $1.2 \mathrm{~cm}$ diameter DC beam designed to operate at $40 \mathrm{keV}$ and 30 $\mathrm{mA}$.

Pressure profiles can be derived from measurements of the electron temperature $\left(\mathrm{T}_{\mathrm{e}}\right)$ and $\left(\mathrm{n}_{\mathrm{e}}\right)$ density with the Thomson scattering (TS) diagnostic. To provide $T_{e}$ and $n_{e}$ profile measurements as a function of time, a multipulse system was designed using Nd:YAG lasers. Equilibria for high beta in NSTX will tend to have flux surfaces compressed on the outboard side of the plasma (Fig. 1) The TS system thus uses a backscattering geometry. It gives full radial coverage on the horizontal midplane, with high sensitivity and high spatial resolution at the outer edge.[10] The spatial resolution is about $1.0 \mathrm{~cm}$ at the plasma outer edge, $3-4 \mathrm{~cm}$ at the magnetic axis, and 8-10 $\mathrm{cm}$ at the inner edge.

At present, the diagnostic consists of two $30 \mathrm{~Hz}, 1.6$ joule/pulse Spectra Physics lasers, which are directed through the machine on the horizontal midplane. The beam tangency radius, or point of closest approach to the center of the machine, of $28 \mathrm{~cm}$. This avoids viewing the center stack, which can get hot enough to make measurements at $1 \mu \mathrm{m}$ impossible during high power plasma operations. The beams exit the machine along a long pumping duct and out a window to an absorbing dump. The laser beams are imaged onto a curved array of 36 fiber optic bundles. The bundles transport the imaged light to filter polychromators, which are housed in an accessible, shielded room near the lasers.

\section{DIAGNOSTICS FOR MHD INSTABILITIES}

Once the plasma equilibria are determined, they can be investigated for their stability against MHD modes. When these occur, they usually result in a change in the magnetic topology. Magnetic field lines can break apart and reconnect, forming magnetic islands. The width of the magnetic island is related to the perturbation in the radial field, $\delta \mathrm{B}_{\mathrm{r}}$, and the poloidal magnetic field, $\mathrm{B}_{\theta}$, as follows.

$$
w=4\left(\frac{r q \delta B_{r}}{m q^{\prime} B_{\theta}}\right)^{\frac{1}{2}}
$$

For the helical field lines in a toroidal MFE device, $\mathrm{m}$ is the number of times a field line spirals in the poloidal direction in a toroidal transit. The "safety factor," or q, is the ratio of $m$ to the number of toroidal transits, or $n$, and q' is its radial derivative. For MFE devices like NSTX, the magnetic island widths dictate a diagnostic spatial resolution on the order of a centimeter.

The time scale that diagnostics require is dictated by the frequency of magnetic oscillations associated with the existence of magnetic islands. It is expected to be on the order of the electron drift frequency,

$$
\omega_{*_{e}}=\left(\frac{m T_{e}}{e B r n_{e}}\right) \frac{d n_{e}}{d r}
$$

where $m$ is poloidal mode number, and $T_{e}$ and $n_{e}$ are the electron temperature and density, respectively. For measurements in machines like NSTX, the ability to resolve oscillations in the tens of kilohertz range is required.

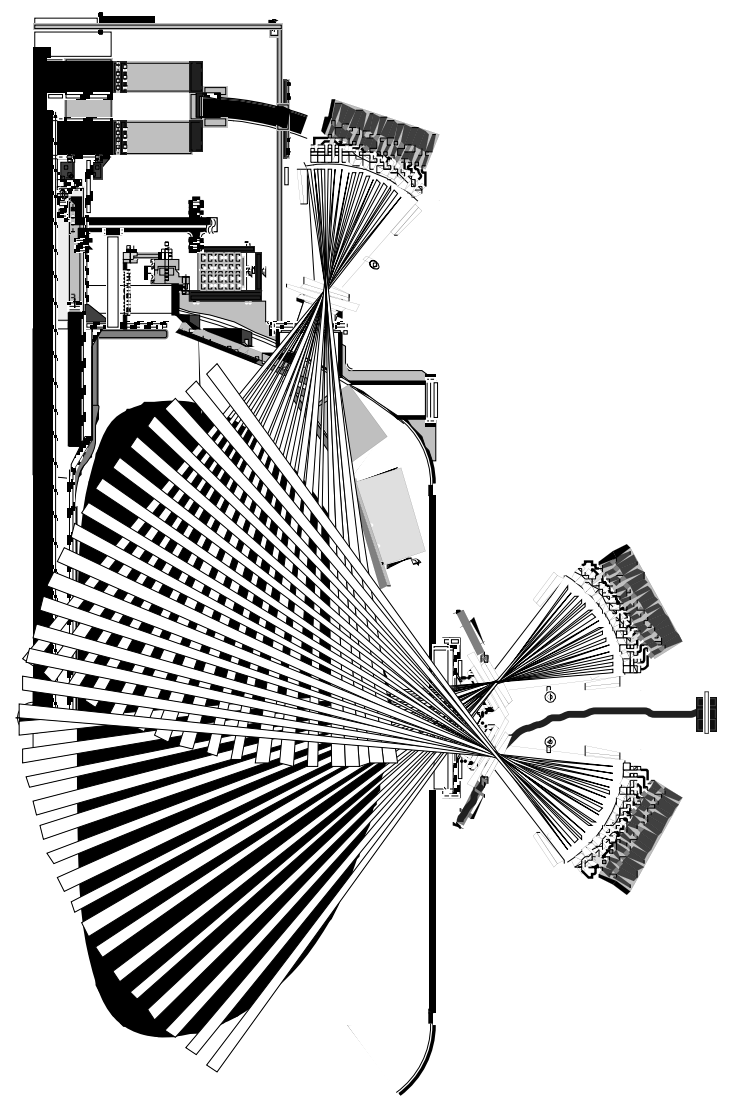

Figure 3. Cross section of NSTX showing layout of soft X-ray arrays and coverage of plasma with detector sightlines.

Among the NSTX diagnostics for studying MHD instabilities are arrays of soft X-ray detectors.[11] There are presently two arrays mounted on the large midplane ports viewing the upper and lower halves of the plasma, 
and a third is mounted on a top flange, viewing the plasma from above. These arrays are shown in Fig. 3. detectors are discrete, large area IRD AXUV silicon photodiodes. Each array has 16 diodes, arranged on an arc around a viewing slot. A moveable slide behind the slot houses several thin foil filters. plasma. The mode has a frequency of about $4 \mathrm{kHz}$, and appears in a viewing region about $100 \mathrm{~cm}$ wide.

An example of an MHD instability measured with the soft X-ray arrays is shown in Fig. 4. The signal is strongest from the detectors viewing closest to the core of the plasma. The instability has poloidal and toroidal mode numbers $\mathrm{m}=1$ and $\mathrm{n}=1$, respectively, and the pattern reflects its motion as it crosses the sightlines of the detectors with time.

\section{Top}

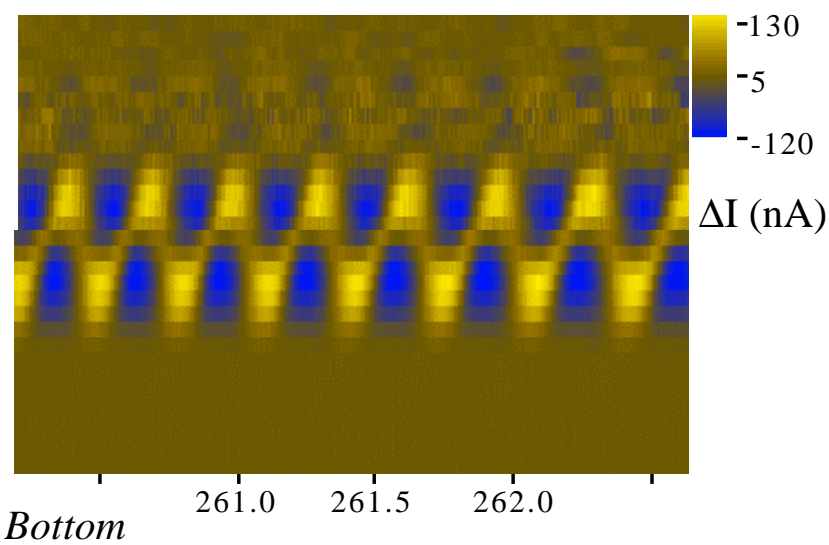

time (ms)

Figure 4. Soft X-ray intensity measured with an array of detectors with views from the top to the bottom of the the plasma. The mode has a frequency of about $4 \mathrm{kHz}$, and appears in a viewing region about $100 \mathrm{~cm}$ wide.

Future plans include operating the arrays with multilayer mirrors for high spectral resolution $(\leq 2 \AA)$ imaging. These will be particularly useful for rejection of the bright core emission, in order to observe MHD instabilities and turbulence at the plasma periphery. For example, the C IV Ly $\alpha$ emission at $33.7 \AA$ can be imaged with a $\mathrm{Ti}$ foil filter-Ti/Cr mirror-diode arrangement, with an estimated background rejection factor of $\sim 100$.

A second set of arrays with an identical viewing geometry, but separated toroidally from the first array by 90 degrees, is being installed. By correlating measurements with the two arrays, the toroidal mode number of MHD instabilities can be identified. Equipped with different filters, they could also provide a fast estimate of $\mathrm{T}_{\mathrm{e}}$ by deducing the electron energy distribution from two different energy ranges.

\section{APPLICATIONS FOR NSTX DIAGNOSTICS IN BASIC SCIENCE}

The NSTX device is also a useful facility for developing diagnostics with applications beyond fusion plasma science. For example, electron and ion temperatures in fusion plasmas have been obtained from measurements of impurity lines with high resolution $\mathrm{X}$ ray crystal spectrometers. This type of instrument is being installed on NSTX specifically to obtain densitysensitive line ratios, which are of particular interest in the study of stellar flares.[12]

The plan is to investigate the L-shell spectra of neonlike systems, such as Fe XVII, and the helium-like systems of low-Z elements, such as neon, magnesium, and silicon. The data obtained from NSTX will be compared with theoretical models, astrophysical data from the Chandra X-ray observatory, and the XMM-Newton Observatory, as well as laboratory plasma data from the Electron Beam Ion Trap (EBIT) at the Lawrence Livermore National Laboratory.

\section{REFERENCES}

[1] M. G. Bell et al., "Overview of DT Results from TFTR,” Nucl. Fusion, vol 35, pp. 1429-1436, December 1995.

[2] L. D. Horton et al., "High Fusion Power Steady State Operation in JET DT Plasmas," Nucl. Fusion, vol 39, pp. 993-1008, August 1999.

[3] Y.-K. M. Peng, "The Physics of Spherical Torus Plasmas," Phys. Plasmas, vol. 7, pp. 1681-1692, May 2000.

[4] J. P. Friedberg, Ideal Magnetohydrodynamics. New York: Plenum, 1987, pp. 108-115.

[5] L. L. Lao et al., "Reconstruction of Current Profile Parameters and Plasma Shapes in Tokamaks," Nucl. Fusion, vol 25, pp. 1611-1622, November 1985.

[6] B. McCormack et al., "Rogowski Loop Designs for NSTX," in Proc.18th IEEE/NPSS Symp. Fus. Engineering, 1999, pp. 306-309.

[7] F. M. Levinton et al., "Improved Confinement with Reversed Magnetic Shear in TFTR," Phys. Rev. Lett., vol. 75, pp. 4417-4421, 11 December 1995.

[8] E. J. Strait et al., "Enhanced Confinement and Stability in DIII-D Discharges with Reversed Magnetic Shear," Phys. Rev. Lett., vol. 75, pp. 4421-4424, 11 December 1995.

[9] F. M. Levinton et al., "Magnetic Field Pitch-Angle Measurements in the PBX-M Tokamak Using the Motional Stark Effect," Phys. Rev. Lett., vol. 63, pp. 2060-2063, 1989.

[10] D. Johnson et al., "Multipulse Thomson Scattering System for the National Spherical Torus Experiment," Rev. Sci. Instrum., vol. 70, pp. 776-779, January 1999.

[11] D. Stutman et al., "Ultrasoft X-ray Imaging System for the National Spherical Torus Experiment," Rev. Sci. Instrum., vol. 70, pp. 572-576, January 1999.

[12] M. Bitter et al., "X-ray spectroscopy at the National Spherical Torus Experiment," $7^{\text {th }}$ Int. Colloq. Atomic Spectra and Oscillator Strengths for Astrophysical and Laboratory Plasmas, Belfast, Northern Ireland, August 59, 2001. 


\section{External Distribution}

Plasma Research Laboratory, Australian National University, Australia

Professor I.R. J ones, Flinders University, Australia

Professor J oão Canalle, Instituto de Fisica DEQ/IF - UERJ , Brazil

Mr. Gerson O. Ludwig, Instituto Nacional de Pesquisas, Brazil

Dr. P.H. Sakanaka, Instituto Fisica, Brazil

The Librarian, Culham Laboratory, England

Library, R61, Rutherford Appleton Laboratory, England

Mrs. S.A. Hutchinson, JET Library, England

Professor M.N. Bussac, Ecole Polytechnique, France

Librarian, Max-Planck-Institut für Plasmaphysik, Germany

J olan Moldvai, Reports Library, MTA KFKI-ATKI, Hungary

Dr. P. Kaw, Institute for Plasma Research, India

Ms. P.J . Pathak, Librarian, Insitute for Plasma Research, India

Ms. Clelia De Palo, Associazione EURATOM-ENEA, I taly

Dr. G. Grosso, Instituto di Fisica del Plasma, Italy

Librarian, Naka Fusion Research Establishment, J AERI, J apan

Library, Plasma Physics Laboratory, Kyoto University, J apan

Research Information Center, National Institute for Fusion Science, J apan

Dr. O. Mitarai, Kyushu Tokai University, J apan

Library, Academia Sinica, Institute of Plasma Physics, People's Republic of China

Shih-Tung Tsai, Institute of Physics, Chinese Academy of Sciences, People's Republic of China

Dr. S. Mirnov, TRINITI, Troitsk, Russian Federation, Russia

Dr. V.S. Strelkov, Kurchatov Institute, Russian Federation, Russia

Professor Peter Lukac, Katedra Fyziky Plazmy MFF UK, Mlynska dolina F-2, Komenskeho Univerzita, SK-842 15 Bratislava, Slovakia

Dr. G.S. Lee, Korea Basic Science Institute, South Korea

Mr. Dennis Bruggink, Fusion Library, University of Wisconsin, USA

Institute for Plasma Research, University of Maryland, USA

Librarian, Fusion Energy Division, Oak Ridge National Laboratory, USA

Librarian, Institute of Fusion Studies, University of Texas, USA

Librarian, Magnetic Fusion Program, Lawrence Livermore National Laboratory, USA

Library, General Atomics, USA

Plasma Physics Group, Fusion Energy Research Program, University of California at San Diego, USA

Plasma Physics Library, Columbia University, USA

Alkesh Punjabi, Center for Fusion Research and Training, Hampton University, USA

Dr. W.M. Stacey, Fusion Research Center, Georgia Institute of Technology, USA

Dr. J ohn Willis, U.S. Department of Energy, Office of Fusion Energy Sciences, USA

Mr. Paul H. Wright, Indianapolis, Indiana, USA 
The Princeton Plasma Physics Laboratory is operated by Princeton University under contract with the U.S. Department of Energy.

\author{
Information Services \\ Princeton Plasma Physics Laboratory \\ P.O. Box 451 \\ Princeton, NJ 08543
}

Phone: 609-243-2750

Fax: 609-243-2751

e-mail: pppl_info@pppl.gov

Internet Address: http://www.pppl.gov 